\title{
Posing Creative Problems: A Study of Elementary Students' Mathematics Understanding
}

\author{
Danielle Bevan $^{1 \star}$ (D), Mary Margaret Capraro ${ }^{1}$ (D)
}

${ }^{1}$ Department of Teaching, Learning and Culture, Texas A\&M University, College Station, TX, USA
${ }^{\star}$ Corresponding Author: dbevan114@tamu.edu

Citation: Bevan, D., \& Capraro, M. M. (2021). Posing Creative Problems: A Study of Elementary Students' Mathematics Understanding. International Electronic Journal of Mathematics Education, 16(3), em0654. https://doi.org/10.29333/iejme/11109

\begin{tabular}{|c|c|}
\hline ARTICLE INFO & ABSTRACT \\
\hline Received: 11 Dec. 2020 & Posing problems in the mathematics classroom can enhance students' learning experiences and allow them to \\
\hline Accepted: 14 May 2021 & $\begin{array}{l}\text { produce problems in a realistic context. Students do not always associate positive feelings with mathematics. } \\
\text { Problem-posing activities can positively impact students' mathematical understanding while allowing for } \\
\text { freedom of expression. Conducted within a larger multi-year study }(N=35) \text {, the present study utilized a subset of } \\
\text { data }(n=11) \text { on elementary students. The primary focus was to understand how a problem-posing intervention } \\
\text { can increase students' mathematical understanding and ability to pose solvable problems. Problems posed by } \\
\text { students were coded based on their solvability and then were further analyzed for their realism, context, and } \\
\text { flexibility in computational terminology as well as the correct alignment of the word problem with the student's } \\
\text { written equation. Results suggest elementary students can create solvable word problems within a variety of } \\
\text { different contexts. }\end{array}$ \\
\hline
\end{tabular}

Keywords: attitudes, elementary students, mathematical creativity, problem posing, solvable problems

\section{INTRODUCTION}

Problem-posing activities can be used by teachers as a strategy to improve students' interest in mathematics. One possible factor that may influence students' interest towards mathematics is their perceptions regarding the degree of creativity and flexibility as well as the freedom of expression offered through engagement in mathematical tasks. Creativity is the use of divergent thinking to create one's own novel idea or realistic scenario (Aljughaiman \& Mowrer-Reynolds, 2005; Isaksen, Dorval, \& Treffinger, 2000; Runco, 2007). There is a general misconception that one cannot be flexible and creative in mathematics classrooms. However, as Devlin (2000) said, "Mathematics is not about numbers, but it is life. It is about the world in which we live. It is about ideas. And far from being dull and sterile as it is so often portrayed, it is full of creativity" (p. 76). In fact, there are varying degrees of creativity afforded to students who engage in mathematics, but their presence in the mathematics classroom largely depends on varied instructional approaches and providing students an outlet to be creative in their thinking. For example, although interest in mathematics generally decreases throughout adolescence, supporting and encouraging creative thought in the learning process has been shown to actually increase interest in mathematics among adolescents (Walkington \& Bernacki, 2015). Encouraging flexible thought by allowing students to pose their own problems improves both their mathematics understanding and interest, and these are important for student success in everyday life. In this study, we examined the posed real-world word problems of elementary students when given pictures and graphs.

Problem posing is an instructional strategy that can utilize creativity during mathematical instruction. Multiple studies have found that incorporating creative activities positively increases students' interest towards mathematics (Akay \& Boz, 2010; Candiasa, Santiyadnya, \& Sunu, 2018; Guvercin, Cilavdaroglu, \& Savas, 2014; Seechaliao, 2017; Walkington, 2017; Walkington \& Bernacki, 2015) and that problem posing in particular can increase student engagement (Priest, 2009) and interest (Walkington \& Bernacki, 2015). Additionally, posing problems requires higher level thinking and flexibility of thought on the part of the student. Problem-posing instruction can also be beneficial for teachers (Cai \& Hwang, 2019; Xu et al., 2020), as it can provide the teacher greater insights into their students' understanding or misunderstanding of various mathematics topics.

Such insights mean that problem-posing instruction can be more beneficial in a classroom than traditional problem-solving instruction. Merely solving problems does not always provide an accurate indication of a student's mathematical understanding because solving word problems requires a certain specific skill set and mathematical content knowledge (Goldin, 2013). Despite the benefits of the instructional style, the posing of problems is not widely used by mathematics teachers, though it is a strategy that should be included in teaching practices (English, 2020; National Council of Teachers of Mathematics [NCTM], 2000). This is 
because few other strategies encourage deeper and richer thinking in mathematics, which can enhance a student's interest towards mathematics while improving teacher assessment of student progression in mathematics comprehension.

\section{Fostering Problem Posing in Mathematics Classrooms}

Posing problems in the mathematics classroom can enhance students' learning experiences and allow students to produce novel variations in a realistic context. In fact, developing novel methods to solve problems can provide a student greater autonomy in their learning and increase their confidence in mathematics (Lowrie, 2002). Improving students' mathematical confidence can be affected by the teacher utilizing three instructional practices: a) providing a variety of opportunities to work with mathematical concepts (Calabrese \& Capraro, in press), b) sharing and modeling mathematical ideas with other students in a safe environment (English, 2020), and c) challenging activities aligned to the abilities of the students (Fennema et al., 1996; Leikin \& Elgrably, 2020). These practices place most of the responsibility of learning on the student rather than the teacher. Providing students opportunities to work through posing a problem and feel comfortable enough to make mistakes and ask questions can lead to developing more confidence towards mathematics. Furthermore, facilitating discussions in mathematics classrooms allows for students to discuss their thoughts in an organized manner. In fact, classroom discussions help students pose problems and allow them to talk through their unique problem-solving processes (Gavin \& Casa, 2012). Discussions during mathematics lessons can unpack mathematical problems and guide students in their learning because guiding questions can be asked by the teacher to encourage students to elaborate on their thought processes (Carpenter et al., 2015). In these ways, teachers can nurture students' learning by providing them ownership of their learning.

Groundwork for independent learning can be supplemented by additional strategies for developing mathematical ideas, including using games (Chang et al., 2011) and diagrams (Charalambous, Kyriakides, \& Philippou, 2003) to assist in the construction of word problems. Thus, incorporating problem-posing activities in mathematics classrooms should be an essential component of classroom instruction. Problem posing can also be valuable for elementary children because they are perceptive about how context is presented to them (Chapman, 2006). Linking mathematics to their real-world experiences (Quintero, 2004) can provide this important context for students. Effective and thoughtful implementation of such strategies makes a teacher's role vital in problem-posing activities (Silver \& Cai, 2005). With supportive learning environments and the ability to engage with challenging mathematical concepts, students can effectively learn difficult mathematics concepts using problem-posing strategies. Strategies and implementation may look different from classroom to classroom, but the end goal remains the same: engaging students in the creation of their own mathematical problems.

\section{The Benefits of Problem Posing}

There are a variety of definitions for what problem posing entails. One definition frames problem posing as the process of students formulating meaningful problems using personal interests (Stoyanova \& Ellerton, 1996). Problem posing can be both the creation of a novel problem and the slight restructuring of given problems (Silver, 1994). There are three classifications of problems students can pose: free, semi-structured, and structured. A problem classified as "free" means a student posed the problem without guidelines or information being provided, "semi-structured" is when a student is given a situation and applies prior mathematical knowledge when posing a problem, and a posed problem is classified as "structured" when a student is asked to create a word problem using a given situation (Stoyanova \& Ellerton, 1996).

Problem posing requires creative thinking and a more complex understanding of mathematical concepts from students than strictly solving word problems. Problem posing also requires students to use previous knowledge and real-world applications when developing problems. The real-world application and creativity used in problem-posing instruction necessitates that students think flexibly and critically. Additionally, increasing opportunities for students to use creativity and real-world applications in their learning allows them to become more engaged, leading to increased interest towards mathematics (Cankoy, 2014; Chang et al., 2011; Rosli et al., 2014; Sugito et al., 2017; Sung, Hwang, \& Chang, 2016; Toluk-Ucar, 2009). This is perhaps because when students use their own interests or their classmates' or their teacher's names in problems they pose or pose problems about a particular motivating topic, they realize that mathematics is relevant to their personal interests and lives (Winograd, 1991). Furthermore, problem posing has been shown by previous researchers to increase students' problem-solving skills and confidence in mathematics (Cifarelli, 2015; English, 2020; Silver \& Cai, 1996). Problem posing can thus provide a powerful learning experience for students while allowing them to realize that mathematics can be a creative subject, which can potentially lead to increased interest and confidence in the topic and improved mathematics understanding.

Problem posing can also benefit teacher lesson planning and instruction. Because misconceptions are common when learning mathematics concepts, providing opportunities to pose problems allows for teacher insight into their students' alternate understanding or prior mathematics knowledge (Kilic, 2017). Composing a solvable problem can indicate a student's mathematical understanding of various concepts, and a poorly written one can reveal underdeveloped aspects of a student's mathematical understanding (Chang et al., 2011; Toluk-Ucar, 2009). A solvable posed problem includes enough information and context to solve the problem. With the information attained from a student's posed problems, a teacher can introduce specific lessons and strategies into the classroom to better aid that student's or a group of students' learning and mathematical understanding.

A previous study conducted by Bevan et al. (2019) examined a group of students who displayed positive attitudes towards mathematics during a problem-posing intervention $(N=35)$. For the purposes of this study, researchers identified students who had the highest increase in their attitude scores towards mathematics $(n=11)$ and analyzed their posed problems. During the current study, researchers examined the work of these particular students qualitatively to further understand how they posed problems as well as the relationship between these students and their mathematics understanding. More broadly, the researchers' 
purpose was to determine the effect of problem-posing intervention activities on elementary students' mathematical understanding and ability to pose solvable word problems.

\section{METHODS}

The present study is situated within the larger multi-year study (i.e., Bevan et al., 2019) and utilized a subset of data $(n=11)$ of elementary students' responses collected during Spring 2019. The primary focus of the present study was to understand how a problem-posing intervention can increase students' mathematical understanding and ability to pose solvable word problems by qualitatively analyzing the responses of the students who had the greatest increase in attitudes towards problem posing as determined during the larger study. The classification of problems used for this study were semi-structured. According to Van Harpen and Sriraman (2012), "A problem-posing situation is referred to as semi-structured when students are given an open situation and are invited to explore the structure of that situation and to complete it by applying knowledge, skills, concepts, and relationships from their previous mathematical experiences" (p. 205). During our interventions, we asked students to pose problems using real-world information we provided and to write an equation that matched the posed problem. This provided some structure in their learning while still allowing students freedom to develop their own problems. For the purposes of our study, we define "equation" as an open standard mathematical statement with a blank or variable written after the equal sign (Powell, 2012). The unique aspect of this study is the application of classification techniques, such as whether a problem was solvable or realistic and characteristics of the posed problem, to understand similarities among students' problem-posing responses.

\section{Participants}

The targeted second- and fourth-grade (ages 7-9) elementary students $(n=11)$ from the larger study (i.e., Bevan et al., 2019) were the participants for this study. All were enrolled in two Title 1 schools within one district in the southwestern United States. The U.S. Department of Education (n.d.) describes the purpose of Title 1 as "providing funds to provide additional learning support, ensuring that all children have a fair, equal, and significant opportunity to obtain a high-quality education and reach, at a minimum proficiency on challenging State academic achievement standards and assessments". Each school had on average 25 students per classroom and two to three classrooms at each grade level. Between the two schools, there were seven second-grade students and two fourth-grade students who were the main focus of this study. The demographics for these two schools mirrored those of the district: $47.5 \%$ White, 27.6\% Hispanic, 21.2\% African American, and 4\% others. Parental consent and student assent were obtained through the university Internal Review Board

\section{Instruments}

Researchers developed six tasks (i.e., four problem-solving and two problem-posing tasks) to be administered before and after the intervention. The difficulty of the tasks was adapted to each grade level (second and fourth) and built on the state objectives, which were based on the standards from the National Council of Teachers of Mathematics (2000). Content validity of the problemposing part of the study was verified by two eminent mathematics professors who possess strong research skills and various problem-posing publications and who were not part of this research study. Examples of second-grade expectations included using a pictograph of zoo animals and a farm picture to pose problems using either addition or subtraction, while fourth graders were asked to pose two-step problems with all four operations when provided with a picture of a cake cut up in fractional parts and a scenario where students start off with $\$ 20$ and select sandwiches to purchase from a menu. The six tasks were first administered at the beginning of the semester in early January before the intervention activities began. The exact same six tasks were administered four months later at the end of the semester in early May. For the purposes of this study, we only focus on the results from the problem-posing tasks.

The six task responses were evaluated by two researchers whose duties included working together to evaluate the written work of the students' posed problems. The researchers developed a problem-posing rubric to assess the problems posed on structure or context (matched the picture, graph, table prompt provided), mathematical equation (the set up matched the problem posed), and appropriateness (problem was realistic and solvable). The researchers discussed any discrepancies until they reached $100 \%$ agreement. Additionally, researchers analyzed student responses to two problem-posing activities that took place during the intervention period.

\section{Intervention}

Preservice teachers (PSTs) who were trained by university faculty met with the second-and fourth-grade students once a week for ten weeks. They met with approximately four students in each of their small groups as they rotated through their mathematics learning centers for 15-20-minute intervals. During the problem-posing groups, elementary students were provided with realworld pictures, objects, or manipulatives to use when they posed problems. During the ten intervention lessons, which were aligned with the state standards on content required to be covered over each school year at different grade levels, the elementary students engaged in hands-on activities focused on posing solvable problems. The PSTs encouraged students to evaluate their novel problems by determining whether they were solvable, realistic, and formulated appropriately for the specific problem scenario (i.e., picture, graph or equation) they were provided. Activities involved both oral and written tasks.

Two activities, those for week five and week eight of the intervention, were chosen for analysis to determine if the elementary students used equations to develop word problems throughout the intervention period, which allowed researchers to evaluate if they were making connections between the problem posed and the equation provided at specific points in time. For example, 


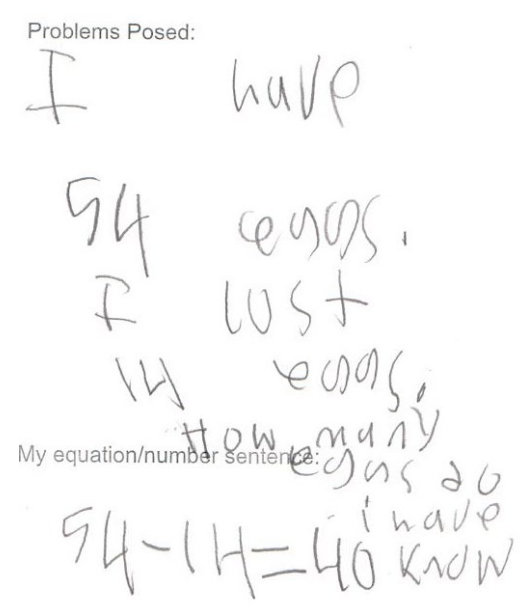

(a)

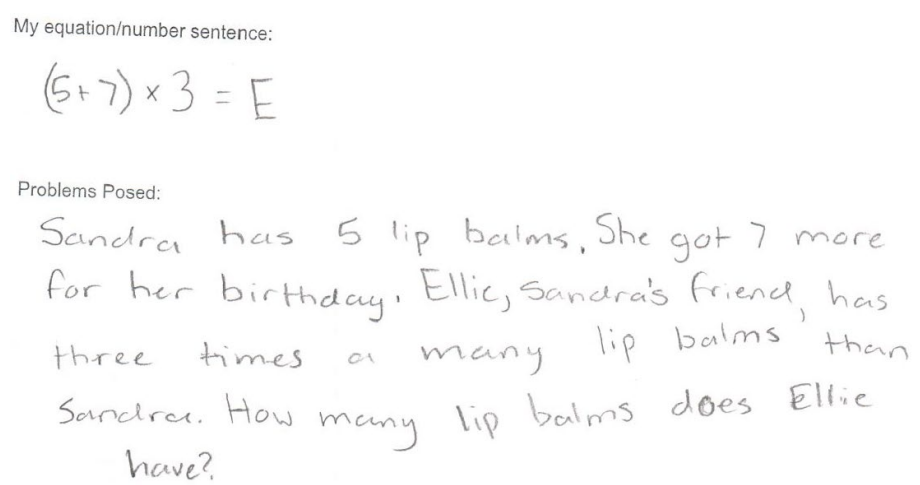

(b)

Figure 1. (a) Second- Grade Easter Egg Responses; (b) Fourth-Grade Easter Egg Responses

during week five, elementary students worked in pairs and were asked to pick an Easter egg that contained a letter corresponding to an equation and then directed to pose their own word problem based on the provided equation. As depicted in Figures 1a and $\mathbf{1 b}$, younger students' content focused on addition and subtraction while upper elementary student content included addition, subtraction, multiplication, and division. The activity for week eight, the popsicle stick activity, required students to choose five or seven sticks depending upon grade level-two or three with numbers, one or two with an operation $(+,-, x$, or $\div)$ and one with an = sign. Students would then form an equation and pose a problem to match their equation. During other intervention activities, students were provided pictures, menus, grocery advertisements, and toys and asked to pose either a one- or a two-step problem with one or two operations as a constraint.

\section{DATA ANALYSIS}

Researchers qualitatively analyzed responses from the two pre- and post-intervention tasks and the two selected activity intervention tasks. Qualitatively analyzing the students' responses to the different tasks gave insight into the students' mathematical understanding. Each student's response was coded first on whether a problem was posed (i.e., did the student ask a question or write a statement?). Once this step was determined, each posed problem was classified as solvable or not. Responses were then analyzed using four criteria to determine if the posed problem had a relationship to the equation provided. Researchers employed descriptive coding (Saldaña, 2016) and keywords-in-context (Leech \& Onwuegbuzie, 2007) to read responses and identify common themes, words, and methods. This coding was used to find similarities and differences between the students' responses. Data were then coded and categorized then cross compared into themes. Any discrepancies were discussed between two researchers until 100\% agreement was reached.

\section{RESULTS}

In order to delve deeper into the mathematical understanding of the targeted students than initially done in the Bevan et al. (2019) findings, we examined the students' posed problems through a variety of lenses using the methods described above. First, the researchers examined the posed problems ( $n=66$; six total tasks from each of the 11 students) to determine whether they were solvable or not. Thirty-six were categorized as solvable and 30 as unsolvable posed problems. An example of an unsolvable posed problem is the following written by a second-grade student: "Thirets [sic] 2 bears at the zoo, 10 wolfs [sic], 7 tigers, 3 zebras and 40 giraffe [sic]." This student did not pose a question stem for the problem thus leaving it unsolvable. An example of a solvable problem was, "I have 54 eggs. I lost 14 eggs. How many eggs do I have know [sic]?," as seen in Figure 1a. Within the responses that were coded as solvable, the problems posed were further analyzed using descriptive coding (Saldaña, 2016) while looking for keywords-in-context (Leech \& Onwuegbuzie, 2007). The following themes emerged: whether the problem was realistic, variety of problem context, flexibility of using various computational terminologies, and correct alignment to the equation. We use these four themes to more deeply describe the results.

\section{Realistic}

Writing a word problem may seem somewhat straightforward but making sure the problem is both solvable and realistic takes an extra level of knowledge and computational and contextual understanding. Most of the problems posed were considered realistic, but a few could be labeled as unrealistic to an adult audience. For example, a solvable and realistic problem written by one of the second-grade students stated, "There are 10 wolfes [sic] and 7 tigers. How many wolfs [sic] and tigers are there together?" This student was using a picture provided to the group and wrote the problem in a format that would allow one of their classmates to solve the problem. There was enough information written to set up an addition problem and solve for the total 


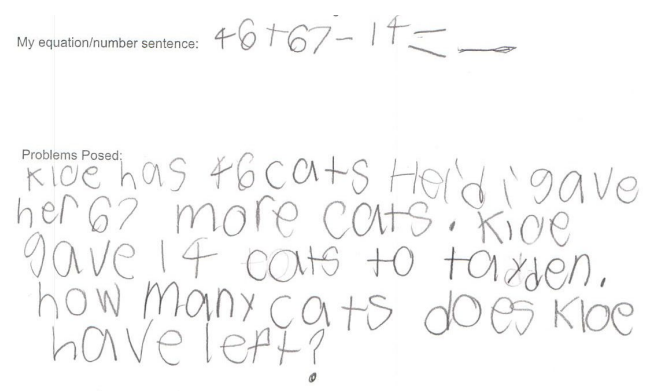

Figure 2. Solvable but Unrealistic Word Problem

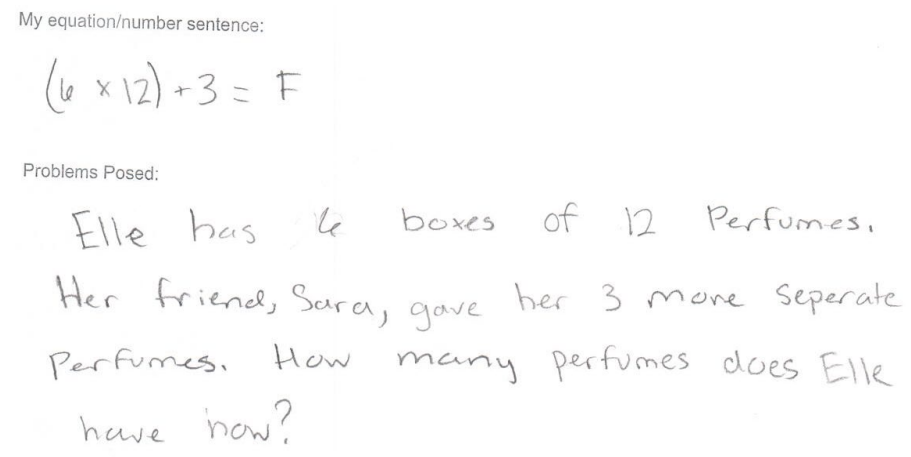

Figure 3. Example of Student Work with Different Context

number of tigers and wolves using the pictograph. Figure 2 shows an example of a solvable but unrealistic word problem: "Kloe has 46 cats. Heidi gave her 67 more cats. Kloe gave 14 cats to Tayden. How many cats does Kloe have left?" This particular problem was written by a second-grade student using the equation, $46+67-14=_{-\ldots}$, chosen from an Easter egg during the week five intervention activity. This word problem is viewed as unrealistic because there is not much context on why an individual would have so many cats. Furthermore, the names used were those of students in the class and not cat breeders. In other words, Heidi, Kloe, nor Tayden would have owned these large numbers of cats thus making the problem unrealistic.

\section{Problem Context}

Another characteristic within the responses is how the students wrote complex problems involving a variety of contexts. They used names that were most often the names of their teacher and classmates with whom they were familiar. Students also used their creativity in using different contexts for their problems. During the pre- and post-intervention problem-posing tasks, students were given pictures and asked to write a problem. Students tended to use the contents of the pictures (zoo animals or cake) when posing problems during this activity, but when students were asked to write a problem in the Easter egg and popsicle stick activities, they would use various contexts that were not eggs or sticks. Students chose to use cars, animals, pencils, food, and beauty products instead when posing problems during these two activities. For example, one of the students picked the equation $(6 \times 12)+3=\ldots$ _ during the Easter egg activity and was asked to write a problem using the equation. This student decided to use perfume as the context and wrote, "Elle has 6 boxes of 12 perfumes. Her friend, Sara, gave her 3 more separate perfumes. How many perfumes does Elle have now?" (see Figure 3). Another example reflected the equation $14+14+14+14=\ldots$ [sic] 14 pizzas. I order 14 more. Somebody give [sic] us 14. I by [sic] 14 pizzas. How many pizza [sic] do we have at [sic] all?" A majority of the students used various familiar contexts while posing their problems. In fact, we found that when students are allowed to write problems in a context they are familiar with, they are more likely to formulate a solvable and interesting word problem.

\section{Flexibility of Operation Terminology}

One characteristic that stood out in student responses was that most students used correct terminology to indicate either subtraction, addition, or multiplication. An interesting finding was that the problems posed by the students in the pre-intervention problem-posing tasks and in the post-intervention problem-posing tasks used correct vocabulary to represent a question by asking "how many" to represent finding the missing result. Most of the students asked their peers to find the total amount of whatever objects they used in their posed problem and used the phrases "in all" or "together" frequently when doing so. This was not always the case, however. One second-grade student wrote, "I whent [sic] to the zoo and saw 7 tigers and 3 bears how many more tigers did I see than bears?" (see Figure 4). This student was using a picture provided to the group, but rather than ask for a total of bears and tigers, this student compared the number of tigers to the number of bears. Solving a comparative problem is challenging, but creating an original comparison problem requires a high level of mathematical understanding.

Another indication of flexibility in operation terminology was when students used the word "more" to represent addition. One student wrote, "Ramsey had 40 pieces of candy she gave 10 to Adrianna then went to buy 15 pieces more how many pieces does she have now?" This student's posed problem indicates the knowledge of "more" representing addition and the phrase "gave 10 


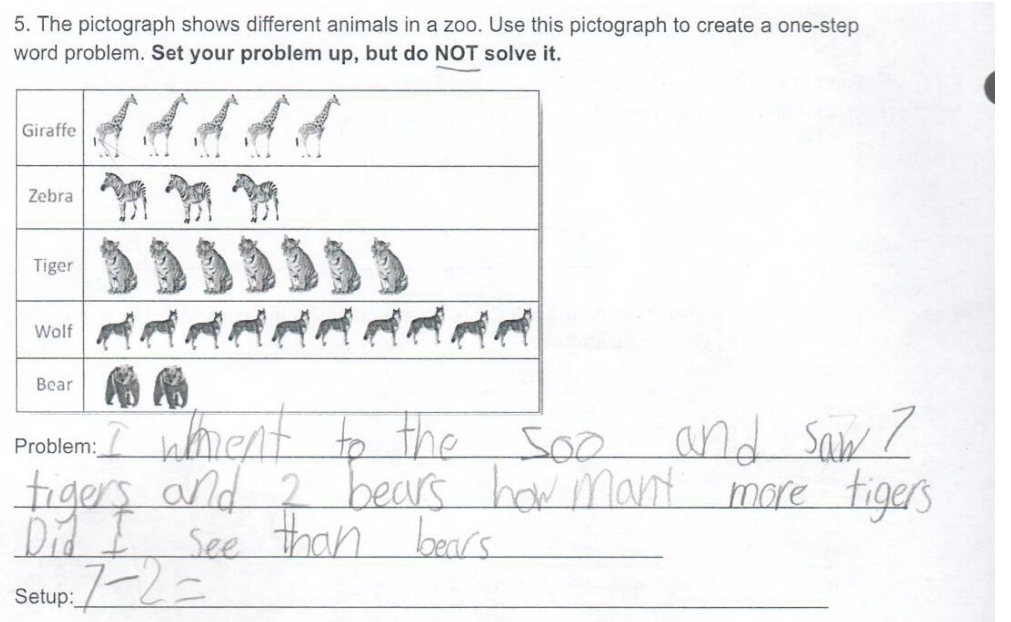

Figure 4. Example of Student Work Using Various Operational Terminology

to Adrianna" as subtraction. Indications of flexibility of operation terminology had the potential to involve more abstract thinking as well.

One fourth-grade student selected the following numbers and operators during the popsicle stick activity: $=,+, \times, 22,15,6$. For their posed problem, they wrote, "Teagan has 22 lip balms. She bought 15 more over the summer. Elle has $6 x$ as many than Teagan. How many balms does Elle have?" What is interesting about this problem is the student understands the relationship between " $\times$ " and times; in an earlier problem they wrote out "times," but in this problem they used the " $x$ " symbol within their word problem to denote "times" or multiplication. By using various terms and methods to represent operations within their problems, the students demonstrated not only their awareness and understanding of certain mathematical vocabulary terminology but also that they were able to successfully use these terms to align with an equation. Additionally, most proved to be successful in their use of the terminology. Table 1 lists out the progression of each student's ability to pose problems from the two pre-intervention tasks, through the two weekly activities, and finally through the two post-intervention tasks.

\section{Correct Alignment to Equation}

Posing word problems can be an enjoyable activity for students and can enable them to gain interest in learning mathematics; however, one of the most important components of problem posing for students is the ability to align the word problem posed to an equation. Word problems are created within scenarios that hopefully are relatable to students and can enable them to strengthen their problem-solving skills. Creating a word problem given only an equation without context requires an even higher level of mathematical understanding. Out of the posed problems denoted as solvable, $88 \%$ of them aligned with a correct equation. Table 2 breaks down only the problems that students correctly aligned to their equations by the following categories: joining, separation, comparison, or multiple operations. Word problems considered as joining included addition in the equation assigned to the student and the problem they posed. Posed problems considered to be separation included subtraction within the equation the student chose and the problem they posed. Comparison problems were more complex and used the phrase "more than," and, lastly, multiple operations were two-step problems that included addition and subtraction or addition and multiplication.

During the popsicle activity, one fourth-grade student the following numbers and operators: $15,20,-,+, 14,=$. The equation they created was $20+15-14=\ldots$. Using this equation, the student posed the following problem: "I had 20 pickels [sic]. I went to the store and bought 15 more then I gave 14 away to my friend how many pickels [sic] did I have left?" We noticed the student understood the relationship between joining items they already possessed and items they bought at the store, and they successfully related this understanding to the operation of addition. This student also understood that giving away pickles meant they would have a smaller amount of pickles and was able to correctly connect this transaction to the operation of subtraction. Examining these problems demonstrated that some students had the ability to make a strong connection between the problems they posed and the equation given to them.

\section{IMPLICATIONS}

Including activities such as problem posing into a mathematics curriculum helps improve students' mathematical understanding. Although teaching is complex and incorporating a new teaching strategy can be difficult, the benefits of doing so may outweigh the challenges. Teachers can utilize problem-posing activities in their lessons to provide opportunities to create more interest among students in their own learning. Given the examples provided in our study, a teacher can use their students' responses to gauge their mathematical knowledge and where there is room for improvement. For instance, as shown in Table 1, our participants wrote problems involving joining "things" and asked for a grand total or "how many are there now?" Students were also able to connect words to varying operations. Relational thinking is the foundation for better understanding of more complex and abstract concepts children will learn throughout their mathematics education (Carpenter et al., 2015). 
Table 1. Student Progression Throughout Intervention

\begin{tabular}{|c|c|c|c|}
\hline Student \# & Pre-Task & Intervention Activities & Post-Task \\
\hline 2.1 & Left both tasks blank. & $\begin{array}{c}\text { Wrote one join problem-"how many all together?" } \\
\text { Wrote a 2-step separation problem-"how many toys } \\
\text { does he have now?" }\end{array}$ & $\begin{array}{l}\text { Created two join problems, both of which asked, } \\
\text { "how many all together?" }\end{array}$ \\
\hline 2.2 & $\begin{array}{l}\text { Created a solvable joining } \\
\text { problem and asked, "how } \\
\text { many in all?" }\end{array}$ & $\begin{array}{l}\text { Wrote one separation problem-"how many toys does } \\
\text { he have now?" } \\
\text { Wrote a 2-step joining problem-"how many do I have } \\
\text { now?" }\end{array}$ & $\begin{array}{l}\text { Created a similar joining problem as the pre-task } \\
\text { and asked, "how many now?" }\end{array}$ \\
\hline 2.3 & Left both tasks blank. & $\begin{array}{l}\text { Wrote one separation problem-"how many toys does } \\
\text { he have now?" } \\
\text { Wrote a 2-step joining problem-"how many does he } \\
\text { have now?" }\end{array}$ & $\begin{array}{c}\text { Created two multistep problems rather than } \\
\text { leaving the problem blank and asked, "how many } \\
\text { are there?" }\end{array}$ \\
\hline 2.4 & $\begin{array}{l}\text { Attempted to create a } \\
\text { problem; however, it was } \\
\text { unsolvable. } \\
\text { Left one task blank. }\end{array}$ & $\begin{array}{l}\text { Wrote one separation problem-"how many does he } \\
\text { have now? } \\
\text { Wrote a 2-step joining problem-how many does he } \\
\text { have now?" }\end{array}$ & $\begin{array}{c}\text { Created two problems rather than leaving a } \\
\text { problem blank and asked, "how many are there } \\
\text { total?" }\end{array}$ \\
\hline 2.5 & $\begin{array}{l}\text { Created two solvable } \\
\text { joining problems and } \\
\text { asked, "how many in all?" }\end{array}$ & $\begin{array}{l}\text { Wrote a 2-step separating and joining problem-"how } \\
\text { many does she have left?" } \\
\text { Wrote a 2-step joining problem-"how many does she } \\
\text { have now?" }\end{array}$ & $\begin{array}{l}\text { Wrote similar joining problems as in the pre-task } \\
\text { and asked, "how many in all," but both problems } \\
\text { lacked solvable context. }\end{array}$ \\
\hline 2.6 & $\begin{array}{l}\text { Attempted to create two } \\
\text { problems; however, both } \\
\quad \text { were unsolvable. }\end{array}$ & $\begin{array}{l}\text { Wrote one separation problem-"how many toys does } \\
\text { he have now?" } \\
\text { Wrote a 2-step joining problem-"how many does he } \\
\text { have now?" }\end{array}$ & $\begin{array}{l}\text { Attempted to create two problems; however, both } \\
\text { were unsolvable. }\end{array}$ \\
\hline 2.7 & $\begin{array}{l}\text { Attempted to create two } \\
\text { problems; however, both } \\
\text { were unsolvable. }\end{array}$ & $\begin{array}{c}\text { Wrote two 2-step separating and joining problems- } \\
\text { "how many do I have left?" }\end{array}$ & $\begin{array}{l}\text { Created a complex separation comparison } \\
\text { problem rather than leaving task blank and asked, } \\
\text { "how many more tigers did I see than bears?" }\end{array}$ \\
\hline 2.8 & $\begin{array}{l}\text { Attempted to create two } \\
\text { problems; however, both } \\
\text { were unsolvable. }\end{array}$ & $\begin{array}{l}\text { Wrote a multistep joining problem-"how many in } \\
\text { all?" } \\
\text { Wrote a 2-step separation and joining problem-"how } \\
\text { many in all?" }\end{array}$ & $\begin{array}{l}\text { Attempted to create two problems; however, both } \\
\text { were unsolvable. }\end{array}$ \\
\hline 2.9 & $\begin{array}{l}\text { Attempted to create two } \\
\text { problems; however, both } \\
\text { were unsolvable. }\end{array}$ & $\begin{array}{l}\text { Wrote a multistep joining problem-"how many in } \\
\text { all?" }\end{array}$ & $\begin{array}{l}\text { Created a problem with local location as context } \\
\text { and asked, "how many are there now?" }\end{array}$ \\
\hline 4.1 & $\begin{array}{l}\text { Attempted to create two } \\
\text { problems; however, both } \\
\text { were unsolvable. }\end{array}$ & $\begin{array}{l}\text { Wrote four 2-step multiplicative comparison and } \\
\text { joining problems--_"how many does she have?" }\end{array}$ & $\begin{array}{l}\text { Created a solvable word problem with context and } \\
\text { asked, "how much did they spend." }\end{array}$ \\
\hline 4.2 & $\begin{array}{c}\text { Attempted to create two } \\
\text { problems, however both } \\
\text { were unsolvable. }\end{array}$ & $\begin{array}{l}\text { Wrote a 2-step separating and joining problem-"how } \\
\text { many do I have left?" }\end{array}$ & $\begin{array}{c}\text { Attempted to create two problems; however, both } \\
\text { were unsolvable. }\end{array}$ \\
\hline
\end{tabular}

Table 2. Categories of Problems Posed

\begin{tabular}{cccc}
\hline Student \# & Joining & Separation & Comparison \\
\hline 2.1 & 2 & 1 & \\
\hline 2.2 & 4 & 1 & \\
\hline 2.3 & 2 & 1 & 1 \\
\hline 2.4 & 3 & 1 & \\
\hline 2.5 & 3 & 1 & \\
\hline 2.6 & 1 & & \\
\hline 2.7 & & & 1 \\
\hline 2.8 & 1 & & \\
\hline 2.9 & 2 & & \\
\hline 4.1 & 1 & & \\
\hline 4.2 & & & \\
\hline
\end{tabular}

Teachers can use this information to direct their lessons to more complex types of problems and help work with their students on how to write subtraction or comparison problems. For example, if Table 2 reflected a particular teacher's classroom, we suggest they engage in working with students to write separation and multiple operation problems because most students showed proficiency in writing joining problems. Finally, working with students and helping guide them through their learning and talking through their processes can help teachers gain further insights into students' thinking and engage students in their own learning. Our participants were second- and fourth-grade students who sometimes had difficulties writing out their thoughts and speaking through the problems they posed. Teachers can ask guiding questions, either individually or as a class, to encourage their students to verbalize orally and through the written word in order to build their confidence in mathematics (Carpenter et al., 2015). Embracing different activities can enhance learning in the classroom and increase students' interest in mathematics. 


\section{CONCLUSION}

There are many benefits of integrating problem-posing activities into early mathematics classrooms. One benefit is developing flexibility in students' thinking when having to create solvable word problems. When we examined the students $(n=11)$ from the prior study (i.e., Bevan et al., 2019) who experienced the highest increases in their mathematical attitudes, we determined they were more likely to create solvable word problems within different contexts. We also concluded that, similar to what prior researchers (Chang et al., 2011; Toluk-Ucar, 2009) have found, examining the responses from second- and fourth-grade students provides insights into their levels of mathematical understanding and also where there is room for improvement. Limitations in our study include sample size and duration of the intervention. However, though our study analyzed specific tasks from a small sample of students and occurred only over a 10-week period, our findings help further the literature by demonstrating that elementary students who are engaged in problem-posing activities in their mathematics classroom can improve their understanding of mathematics (Chang et al., 2011; Sugito et al., 2017; Sung et al., 2016).

Most students, in fact, showed certain improvements from before the intervention to after the intervention. Improvements included posing word problems that were solvable and sometimes contained multiple steps. Students demonstrated a strong ability in connecting the word problem they created to the chosen equation. Incorporating different contexts within problems motivated student creativity, autonomy, and interest in posing and solving problems because the students were able to choose the context of the problem. Guiding students by asking them to pose semi-structured problems by providing them pictures or other supports when building an equation provides a balance between giving the student freedom in their learning and making sure the student is learning the correct content. Finally, allowing students the freedom to create problems incorporating what interests them promotes ownership in their learning and provides teachers a window into their students' learning.

The posing of word problems involves more than writing the problem; it also includes discussion about the context and solvability of a word problem produced by a student (Gavin \& Casa, 2012). During the current study, discussions took place in small groups with the assigned PST and the students' peers and allowed students to exchange and discuss their posed problems. These discussions allowed for students to grow in their mathematical understanding. Ultimately, aiding elementary students in gaining confidence in their own mathematics skills through problem posing can lead to deeper mathematical understanding and more interest in the subject. Allowing for creativity in the mathematics classroom allows for more opportunities to encourage positive understanding towards mathematical concepts and the application of mathematics in real-world settings.

Author contributions: All authors have sufficiently contributed to the study, and agreed with the results and conclusions.

Funding: No funding source is reported for this study.

Acknowledgement: Thanks to Drs. Luciana Barroso, Mary Margaret Capraro, Robert M. Capraro, Jamaal Young, and the Aggie STEM team for providing the data used for this study.

Declaration of interest: No conflict of interest is declared by authors.

\section{REFERENCES}

Akay, H., \& Boz, N. (2010). The effect of problem posing oriented analyses-II course on the attitudes toward mathematics and mathematics self-efficacy of elementary prospective mathematics teachers. Australian Journal of Teacher Education, 35(1), 5975. https://doi.org/10.14221/ajte.2010v35n1.6

Aljughaiman, A., \& Mowrer-Reynolds, E. (2005). Teachers' conceptions of creativity and creative students. Journal of Creative Behavior, 39(1), 17-34. https://doi.org/10.1002/j.2162-6057.2005.tb01247.x

Bevan, D., Williams, A. M., \& Capraro, M. M. (2019). Strike a pose: The impact of problem-posing on elementary students' mathematical attitudes and achievement. In J. Novotná \& H. Moraová (Eds.), Proceedings of the 2019 International Symposium on Elementary Mathematics Teaching (pp. 80-87). Charles University.

Cai, J., \& Hwang, S. (2019). Learning to teach through mathematical problem posing: Theoretical considerations, methodology, and directions for future research. International Journal of Educational Research. https://doi.org/10.1016/j.ijer.2019.01.001

Calabrese, J. E., \& Capraro, M. M. (in press, 2021). Word problem taxonomy and problem-posing: A professional development exploration. Primary Mathematics.

Candiasa, I. M., Santiyadnya, N., \& Sunu, G. K. A. (2018). Using puzzle to encourage students to do problem posing. Proceedings of the International Conference on Mathematics and Natural Sciences, 2017, 1-6. https://doi.org/10.1088/1742$6596 / 1040 / 1 / 012025$

Cankoy, O. (2014). Interlocked problem posing and children's problem posing performance in free structured situations. International Journal of Science and Mathematics Education, 12(1), 219-238. https://doi.org/10.1007/s10763-013-9433-9

Carpenter, T. P., Fennema, E., Franke, M. L., Levi, L., \& Empson, S. B. (2015). Children's mathematics: Cognitively guided instruction. Heinemann.

Chang, K. E., Wu, L. J., Weng, S. E., \& Sung, Y. T. (2011). Embedding game-based problem-solving phase into problem-posing system for mathematics learning. Computers \& Education, 58(2), 775-786. https://doi.org/10.1016/j.compedu.2011.10.002

Chapman O. (2006). Classroom practices for context of mathematics word problems. Educational Studies in Mathematics, 62(2), 211-230. https://doi.org/10.1007/s10649-006-7834-1 
Charalambous, C., Kyriakides, L., \& Philippou, G. (2003). Testing a comprehensive model for measuring problem solving and problem posing skills of primary pupils. International Group for the Psychology of Mathematics Education, 2, 205-212.

Cifarelli, V. V. (2015). Problem posing as reformulation and sense-making within problem solving. Mathematical Problem Posing, 177-194. https://doi.org/10.1007/978-1-4614-6258-3_8

Devlin, K. (2000). The math gene: How mathematical thinking evolved and why numbers are like gossip. Basic Books.

English, L. (2020). Teaching and learning through mathematical problem posing: Commentary. International Journal of Educational Research, 102. https://doi.org/10.1016/j.ijer.2019.06.014

Fennema, E., Carpenter, T. P., Franke, M. L., Levi, L., Jacobs, V. R., \& Empson, S. B. (1996). A longitudinal study of learning to use children's thinking in mathematics instruction. Journal for Research in Mathematics Education, 27(4), 403-434. https://doi.org/10.2307/749875

Gavin, M. K., \& Casa, T. M. (2012). Nurturing young student mathematicians. Gifted Education International, $29(2), 140-153$. https://doi.org/10.1177/0261429412447711

Goldin, G. (2013). Toward an assessment framework for school mathematics. In R. A. Lesh \& S. J. Lamon (Eds.), Assessment of authentic performance in school mathematics (pp. 73-98). Routledge. https://doi.org/10.4324/9780203053393-9

Guvercin, S., Cilavdaroglu, A. K, \& Savas, A. C. (2014). The effect of problem posing instruction on 9th grade students' mathematics academic achievement and retention. The Anthropologist, 17(1), 129-136. https://doi.org/10.1080/09720073.2014.11891422

Isaksen, S., Dorval, K., \& Treffınger, D. (2000). Creative approaches to problem solving. Kendall Hunt.

Kilic, C. (2017). A new problem-posing approach based on problem-solving strategy: Analyzing pre-service primary school teachers' performance. Educational Sciences: Theory and Practice, 17(3), 771-789.

Leech, N. L., \& Onwuegbuzie, A. J. (2007). An array of qualitative data analysis tools: A call for data analysis triangulation. School Psychology Quarterly, 22(4), 557-584. https://doi.org/10.1037/1045-3830.22.4.557

Leikin, R., \& Elgrably, H. (2020). Problem posing through investigations for the development and evaluation of proof-related skills and creativity skills of prospective high school mathematics teachers. International Journal of Educational Research, 102. https://doi.org/10.1016/j.ijer.2019.04.002

Lowrie, T. (2002). Young children posing problems: The influence of teacher intervention on the type of problems children pose. Mathematics Education Research Journal, 14, 87-98. http://doi.org/10.1007/BF03217355

National Council of Teachers of Mathematics. (2000). Principles and standards for school mathematics.

Powell, S. R. (2012). Equations and the equal sign in elementary mathematics textbooks. Elementary School Journal, 112(4), $627-$ 648. https://doi.org/10.1086/665009

Priest, D. J. (2009). A problem-posing intervention in the development of problem-solving competence of underachieving, middleyear students [Doctoral dissertation, Queensland University of Technology]. https://eprints.qut.edu.au/31740/

Quintero, E. (2004). Problem posing with multicultural children's literature. Peter Lang.

Rosli, R., Capraro, M. M., \& Capraro, R. M. (2014). The effects of problem-posing on student mathematical learning: A meta-analysis. International Education Studies, 7(13), 227-241. https://doi.org/10.5539/ies.v7n13p227

Runco, M. A. (2007). Creativity. Theories and themes: Research, development and practice. Elsevier Academic Press.

Saldaña, J. (2016). The coding manual for qualitative researchers (3rd Ed.). SAGE.

Seechaliao, T. (2017). Instructional strategies to support creativity and innovation in education. Journal of Education and Learning, 6(4), 201-208. https://doi.org/10.5539/jel.v6n4p201

Silver, E. A. (1994). On mathematical problem posing. For the Learning of Mathematics, 14(1), 19-28.

Silver, E. A., \& Cai, J. (1996). An analysis of arithmetic problem posing by middle school students. Journal for Research in Mathematics Education, 27(5), 521-539. https://doi.org/10.2307/749846

Silver, E. A., \& Cai. J. (2005). Assessing students' mathematical problem posing. Teaching Children Mathematics, 12(3), 129-135. https://doi.org/10.5951/TCM.12.3.0129

Stoyanova, E., \& Ellerton, N. F. (1996). A framework for research into students' problem posing in school mathematics. In P. C. Clarkson (Ed.), Proceedings of the $19^{\text {th }}$ Annual Conference of the Mathematics Education Research Group of Australasia (pp. 518525). The Mathematics Education Research Group of Australasia.

Sugito, S., Susilowati, S. M. E., Hartono, H., \& Supartono, S. (2017). Enhancing students' communication skills through problem posing and presentation. International Journal of Evaluation and Research in Education, 6(1), 17-22. https://doi.org/10.11591/ijere.v6i1.6342

Sung, H.-Y., Hwang, G.-J., \& Chang, Y.-C. (2016). Development of a mobile learning system based on a collaborative problem-posing strategy. Interactive Learning Environments, 24(3), 456-471. https://doi.org/10.1080/10494820.2013.867889

Toluk-Uçar, Z. (2009). Developing pre-service teachers understanding of fractions through problem posing. Teaching and Teacher Education, 25(1), 166-175. https://doi.org/10.1016/j.tate.2008.08.003

U.S. Department of Education. (n.d.). Title I - Improving the academic achievement of the disadvantaged. Retrieved March 24, 2021, from https://www2.ed.gov/policy/elsec/leg/esea02/pg1.html 
Van Harpen, X. Y., Sriraman, B. (2012). Creativity and mathematical problem posing: An analysis of high school students' mathematical problem posing in China and the USA. Educational Studies in Mathematics, 82(2), $201-221$. https://doi.org/10.1007/s10649-012-9419-5

Walkington, C. (2017). Design research on personalized problem posing in algebra. In E. Galindo \& J. Newton (Eds.), Proceedings of the Thirty-Ninth Annual Meeting of the North American Chapter of the International Group for the Psychology of Mathematics Education (pp. 195-202). Hoosier Association of Mathematics Teacher Education.

Walkington, C., \& Bernacki, M. (2015). Students authoring personalized "algebra stories": Problem-posing in the context of out-ofschool interests. The Journal of Mathematical Behavior, 40(Part B), 171-191. https://doi/10.1016/j.jmathb.2015.08.001

Winograd, K. (1991, April 3-7). Writing, solving, and sharing original math story problems: Case studies of fifth grade children's cognitive behavior. Paper presented at the American Educational Research Association 1991 Annual Meeting, Chicago, IL.

Xu, B., Cai, J., Liu, Q., \& Hwang, S. (2020). Teachers' predictions of students' mathematical thinking related to problem posing. International Journal of Educational Research, 102. https://doi.org/10.1016/j.ijer.2019.04.005 